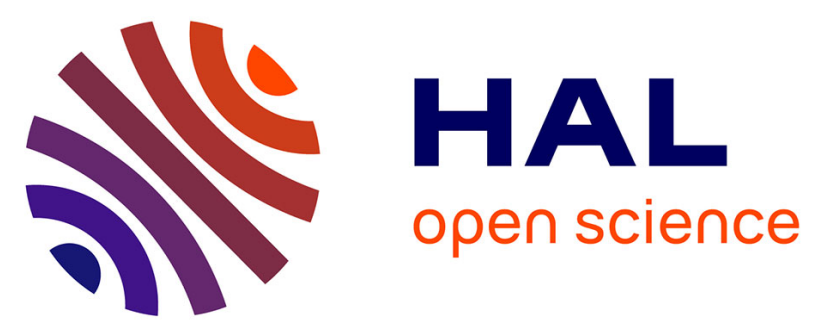

\title{
Energetic Performances of Pure-Silica DDR Zeolite by High-Pressure Intrusion-Extrusion of Electrolyte Aqueous Solutions: A Shock-Absorber with Huge Absorbed Energy
}

Laura Ronchi, Andrey Ryzhikov, Habiba Nouali, T. Jean Daou, Joël Patarin

\section{To cite this version:}

Laura Ronchi, Andrey Ryzhikov, Habiba Nouali, T. Jean Daou, Joël Patarin. Energetic Performances of Pure-Silica DDR Zeolite by High-Pressure Intrusion-Extrusion of Electrolyte Aqueous Solutions: A Shock-Absorber with Huge Absorbed Energy. Journal of Physical Chemistry C, 2018, 122 (5), pp.2726-2733. 10.1021/acs.jpcc.7b10995 . hal-03544621

\author{
HAL Id: hal-03544621 \\ https://hal.science/hal-03544621
}

Submitted on 26 Jan 2022

HAL is a multi-disciplinary open access archive for the deposit and dissemination of scientific research documents, whether they are published or not. The documents may come from teaching and research institutions in France or abroad, or from public or private research centers.
L'archive ouverte pluridisciplinaire HAL, est destinée au dépôt et à la diffusion de documents scientifiques de niveau recherche, publiés ou non, émanant des établissements d'enseignement et de recherche français ou étrangers, des laboratoires publics ou privés. 


\title{
Energetic Performances of Pure-Silica DDR Zeolite by High-Pressure Intrusion-Extrusion of Electrolyte Aqueous Solutions: A Shock- Absorber with Huge Absorbed Energy
}

\author{
Laura Ronchi, Andrey Ryzhikov,* Habiba Nouali, T. Jean Daou, ${ }^{\oplus}$ and Joël Patarin*๑
}

Axe Matériaux à Porosité Contrôlée (MPC), Institut de Science des Matériaux de Mulhouse (IS2M), Université de Strasbourg (UDS), Université de Haute Alsace (UHA), UMR CNRS 7361, 3 bis rue Alfred Wemer, F-68093 Mulhouse, France
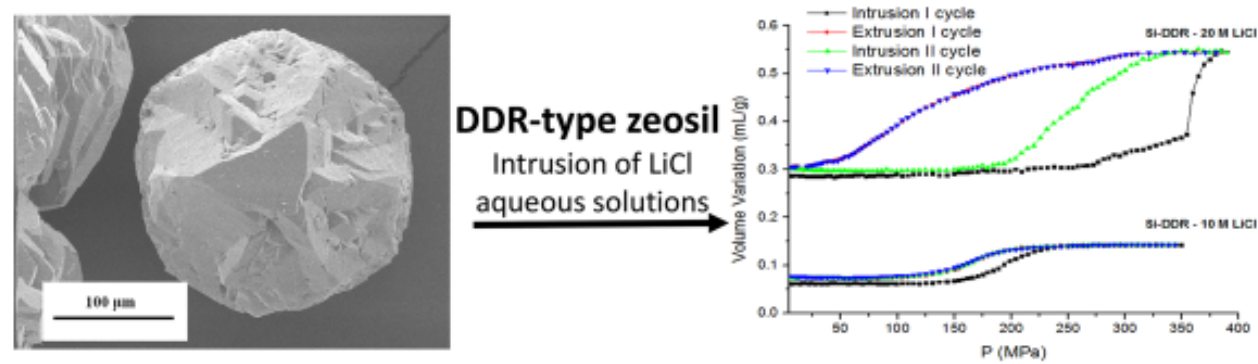

ABSTRACT: Pure-silica DDR-type zeolite (zeosil) displays a porosity composed of two kinds of small cages (pore opening of 4-6 MR) and of a large nonadecahedron cage with pore windows of $8 \mathrm{MR}$. In order to study the energetic performances of this hydrophobic material by high-pressure intrusion-extrusion experiments, water and 10 and $20 \mathrm{M} \mathrm{LiCl}$ aqueous solutions were chosen as nonwetting liquids. The intrusion pressure increases from 60 to $357 \mathrm{MPa}$ when using water and $20 \mathrm{M} \mathrm{LiCl}$ aqueous solution, respectively. The latter pressure is the highest ever found for a zeosil-based system. It is associated with a large intruded volume of $0.26 \mathrm{~mL} / \mathrm{g}$, which is close to the total theoretical porosity of the DDR structure. The corresponding "DDR-20 M LiCl aqueous solution" system demonstrates mainly shock-absorber behavior, and both features (high intrusion pressure and large intruded volume) lead to the highest amount of absorbed mechanical energy for such systems: 93 and $61 \mathrm{~J} / \mathrm{g}$ for the first and the following intrusion cycles, respectively. After intrusion-extrusion of $\mathrm{LiCl}$ aqueous solutions and depending on the concentration of the solution or the number of the intrusion-extrusion cycles, slight distortions of the DDR unit cell are clearly evidenced by $\mathrm{XRD}$ and ${ }^{29} \mathrm{Si}$ MAS NMR analyses. Two possible explanations are advanced to explain such distortions.

\section{INTRODUCTION}

Deca-dodecasil 3R (DDR topology) is a pure-silica zeolite (zeosil) that was synthesized for the first time by $\mathrm{H}$. Gies ${ }^{1}$ in 1986. This zeosil crystallizes in the trigonal symmetry (space group $R \overline{3} \mathrm{~m}$ ) with the following hexagonal cell parameters: $a=$ 13.860 (3) $\AA, c=40.891$ (8) $\AA^{2}$. The structure of this zeosil is composed of three kinds of cages denoted $\left[n^{m}\right]$, where $m$ is the number of $n$-membered rings (MR) defining the faces of the cage. ${ }^{2}$ Thus, the DDR unit cell contains six decahedron, $\left[4^{3} 5^{6} 6^{1}\right]$ cages, nine dodecahedron $\left[5^{12}\right]$ cages, and six nonadecahedron $\left[4^{3} 5^{12} 6^{1} 8^{3}\right]$ cages. The decahedron and dodecahedron cages with volumes of 35 and $70 \AA^{3}$, respectively, are not accessible to $\mathrm{N}_{2}$ adsorption-desorption measurements because the cage openings (4-6 MR) are too small. The volume of the nonadecahedron cage is close to $\sim 350 \AA^{3}$ with a diameter of $8.3 \AA^{3}{ }^{3}$ The three cages give a theoretical total porous volume of $\sim 2940 \AA^{3}$ per unit cell. ${ }^{2}$ This volume converted in $\mathrm{cm}^{3} / \mathrm{g}$ leads to $\sim 0.24 \mathrm{~cm}^{3} / \mathrm{g}$, where $0.17 \mathrm{~cm}^{3} / \mathrm{g}$ is due to the bigger cages (nonadecahedron cages).
The larger cages are connected by $8 \mathrm{MR}$ pore openings of 3.6 $\times 4.4 \AA^{2}$ size that lead to a two-dimensional pore system perpendicular to the $c$ direction. These sizes are suitable for sieving of small gas molecules. In particular, membranes composed of this zeosil show an attractive potential in adsorption and sieving fields, for instance, in the separation of propane/propene ${ }^{4}$ and $\mathrm{CO}_{2} / \mathrm{CH}_{4}^{5,6}$ mixtures. High selectivity is also shown in the dehydrogenation of isobutane and in the dehydration of organic solvents such as methanol or ethanol. $^{8}$

The high hydrophobicity of DDR-type zeosil (Si-DDR hereafter) offers the possibility to use it for energetic applications by high-pressure intrusion-extrusion of water and aqueous solutions in its porosity. When the intrusion of a nonwetting liquid is forced into a lyophobic nanoporous material, forming a so-called heterogeneous lyophobic system 
large interface area. Thus, on the microscopic scale, the intrusion process can be considered as a simultaneous breaking of intermolecular bonds within the liquid and a creation of new interactions with the solid walls. In this way, a conversion of the supplied mechanical energy into interfacial energy occurs. When the pressure is released, three different behaviors can be observed: the mechanical energy can be restored, dissipated, or absorbed depending on the structure, on the hydrophobic character of the material, and on the nature of the intruded liquid. Thus, these systems can display a spring, shock-absorber, or bumper behavior, respectively. Heterogeneous lyophobic systems are studied for applications in automotive and aerospace industries and for industrial security. ${ }^{9-12}$

The first HLSs were conceived of by Professor V. Eroshenko ${ }^{13-16}$ in the mid-1980s using porous solids and metallic alloys as nonwetting liquids. Then, other studies were conducted on quite hydrophobic silica materials intruded with water. ${ }^{17}$ In 2001, our team introduced the use of zeosils as hydrophobic materials in HLSs that allowed us to obtain high intrusion pressure values up to $\sim 180 \mathrm{MPa}$ due to their low pore size. ${ }^{18,19}$ The following works showed that the intrusion of saline solutions improved the energetic performances of the systems and could induce a change in the behavior depending on the salt concentration. ${ }^{20-23}$ For example, the intrusion pressure for the $20 \mathrm{M} \mathrm{LiCl}$ aqueous solution is 7.4 times higher than the one obtained while using water as a nonwetting liquid in the case of LTA-type zeosil.

In the present work, the energetic performances of "Si-DDR. nonwetting liquid" systems are reported, using water and 10 and $20 \mathrm{M} \mathrm{LiCl}$ aqueous solutions as nonwetting liquids. The samples were fully characterized before and after the intrusionextrusion experiments by powder X-ray diffraction (XRD), scanning electron microscopy (SEM), thermogravimetric analysis (TG), $\mathrm{N}_{2}$ adsorption-desorption measurements, and solid-state NMR spectroscopy in order to study the influence of these experiments on the zeosil structure.

\section{EXPERIMENTAL SECTION}

Synthesis. The Si-DDR sample was synthesized according to an adapted procedure published by $\mathrm{H}$. Gies. ${ }^{1}$ The reactants used were Aerosil 130 (Evonik) as the silica source, 1adamantylamine (ADA, Sigma-Aldrich, 97\%) as a structuredirecting agent, and ethylenediamine (ED, Sigma-Aldrich, $>99 \%$ ). The starting gel (molar composition: $1 \mathrm{SiO}_{2} / 0.4$ ADA/4 ED/60 $\mathrm{H}_{2} \mathrm{O}$ ) was introduced in a Teflon-lined stainless-steel autoclave and heated at $180{ }^{\circ} \mathrm{C}$ for 20 days. After the synthesis, the product was filtered, washed with distilled water and ethanol, and then dried in an oven at $70{ }^{\circ} \mathrm{C}$ overnight. At the end, the solid was calcined at $750{ }^{\circ} \mathrm{C}$ under air for $8 \mathrm{~h}$ to completely remove the organic template.

Intrusion-Extrusion Experiments. The intrusion-extrusion of water and $\mathrm{LiCl}$ aqueous solutions was performed at room temperature using a Micromeritics mercury porosimeter (Model Autopore IV), as described in a previous work. ${ }^{24}$

Prior to the analyses, the Si-DDR samples (nonintruded and intruded-extruded ones) were hydrated in an $80 \%$ relative humidity atmosphere for $24 \mathrm{~h}$ in order to set the hydration state.

Powder X-ray Diffraction. XRD patterns of the different samples were recorded on a STOE STADI-P diffractometer in the transmission scan mode equipped with a curved germanium
Measurements were achieved for $2 \theta$ angle values in the $3-50^{\circ}$ range, step of $0.2^{\circ} 2 \theta$, and time $/$ step $=10 \mathrm{~s}$.

Scanning Electron Microscopy. The size and the morphology of the crystals were determined by SEM using a Philips XL 30 FEG microscope.

Nitrogen Adsorption-Desorption Measurements. Nitrogen adsorption-desorption isotherms were performed at 77 $\mathrm{K}$ using a Micromeritics ASAP 2420 apparatus. Prior to the adsorption measurements, the nonintruded sample was out gassed at 90 or $300{ }^{\circ} \mathrm{C}$ overnight under vacuum. The intruded-extruded samples were outgassed at $90^{\circ} \mathrm{C}$ overnight to avoid the dehydroxylation process. The specific surface area and microporous volume $\left(V_{\text {miro }}\right)$ were calculated using the BET and t-plot methods, respectively.

Thermogravimetric Analyses. TG analyses were carried out on a Mettler Toledo STARe apparatus, under air flow, with a heating rate of $5{ }^{\circ} \mathrm{C} / \mathrm{min}$ from 30 to $800{ }^{\circ} \mathrm{C}$

${ }^{29} \mathrm{Si}$ MAS and ${ }^{1} \mathrm{H}-{ }^{29} \mathrm{Si}$ CPMAS NMR Spectroscopy. The NMR spectra were recorded at room temperature on a Bruker Avance II $300 \mathrm{MHz}$ spectrometer, with a double-channel $7 \mathrm{~mm}$ Bruker MAS probe. The recording conditions are given in Table 1.

Table 1. Recording Conditions of the ${ }^{29} \mathrm{Si}$ MAS and ${ }^{1} \mathrm{H}-{ }^{29} \mathrm{~S}$ CPMAS NMR Spectra

$\begin{array}{lcc} & { }^{29} \mathrm{Si} \text { MAS } & { }^{1} \mathrm{H}-{ }^{2} \mathrm{Si} \text { CPMAS } \\ \text { chemical shift standard } & \mathrm{TMS}^{a} & \mathrm{TMS}^{a} \\ \text { frequency }(\mathrm{MHz}) & 59.6 & 59.6 \\ \text { pulse width }(\mu \mathrm{s}) & 2.60 & 5.00 \\ \text { flip angle } & \pi / 6 & \pi / 2 \\ \text { contact time }(\mathrm{ms}) & & 1 \\ \text { recycle time }(\mathrm{s}) & 80 & 6^{b} \\ \text { spinning rate }(\mathrm{kHz}) & 4 & 4 \\ \text { scan number } & 1500 & 30000 \\ \text { a Tetramethylsilane. } & { }^{b} \text { The relaxation time } t_{1} \text { was optimized. }\end{array}$

\section{RESULTS AND DISCUSSION}

Intrusion-Extrusion Isotherms. Because of the small amount of obtained product, only intrusion-extrusion experiments with $\mathrm{LiCl}$ aqueous solutions were performed in this work. For water intrusion-extrusion in Si-DDR, the result previously obtained by our group ${ }^{19,25}$ were used as reference because the sample synthesized in this work and the previous one have very similar features. The pressure-volume diagrams (intrusion-extrusion isotherms) of the " $\mathrm{Si}-\mathrm{DDR}-\mathrm{LiCl}$ aqueous solutions" systems are shown in Figure 1, and the corresponding characteristic data are reported in Table 2.

The "Si-DDR-water" system shows reversible spring behavior with a slight hysteresis because the intruded liquid is completely expelled from the solid when the pressure is released. For all of the cycles, the liquid is intruded at $60 \mathrm{MPa}$ and extruded at 51 $\mathrm{MPa}^{25}$ These values are quite high compared to the ones obtained for other cage-type zeosils $(20-40 \mathrm{MPa}) .^{19,2}$ Characterization of the intruded-extruded sample indicates that the structure is not affected after the intrusion-extrusion experiments. $^{25}$ On the other hand, the intrusion of $\mathrm{LiCl}$ aqueous solutions is slightly irreversible in the first cycle. Compared to the water intrusion, the Si-DDR-10 M LiCl system shows a huge rise (multiplied by 3.2 ) of the intrusion 


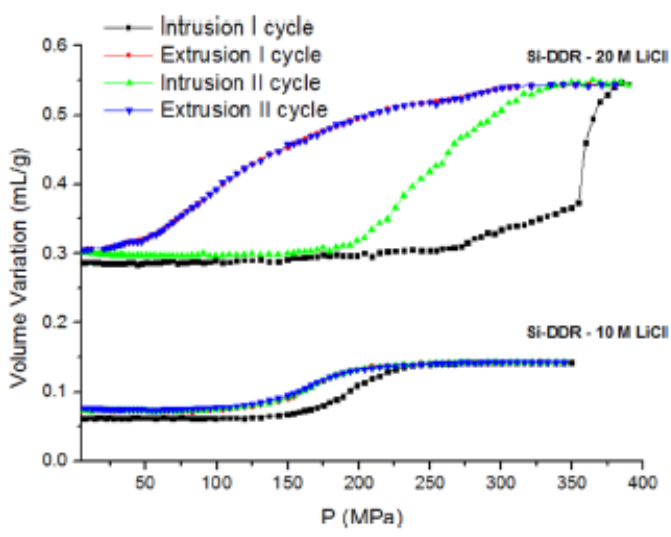

Figure 1. First and second intrusion-extrusion cycles of the Si-DDR$\mathrm{LiCl}$ aqueous solutions systems. For clarity, the intrusion-extrusion isotherms are shifted along the $Y$ axis.

pressure value (193 $\mathrm{MPa}$ ) in the first cycle, while it becomes lower in the next ones $(166 \mathrm{MPa})$. The increase of intrusion pressure with the salt concentration is explained by several hypotheses: (I) a higher surface tension of electrolyte aqueous solution in comparison with water, ${ }^{26,27}$ (II) an osmotic phenomenon, ${ }^{28,29}$ (III) a confinement effect of the nanopore walls, ${ }^{30}$ or (IV) an ion desolvation phenomenon. ${ }^{20,31} \mathrm{~A}$ recent study, dealing with the "FER-type zeosil- $\mathrm{MgCl}_{2} \cdot 21 \quad \mathrm{H}_{2} \mathrm{O}$ " system demonstrated that the electrolyte aqueous solution intruded into the pores was more concentrated $\left(\mathrm{MgCl}_{2} \cdot 10\right.$ $\mathrm{H}_{2} \mathrm{O}$ ) than the initial one. The decrease of the water content and, thus, the higher concentration of the intruded solution could be reasonably the result of the hydrophobic nature of the host zeolite matrix. ${ }^{32}$ These results are a strong argument in favor of the desolvation hypothesis.

The intruded volume in the first cycle is close to $0.08 \mathrm{~mL} / \mathrm{g}$ which is lower than the one found for water intrusion $(0.11$ $\mathrm{mL} / \mathrm{g}){ }^{19}$ The two values are quite consistent with the microporous volume observed for the intruded-extruded sample (see below) because it is known that the density of the water intruded in the hydrophobic zeosil pores is generally about $0.6 \mathrm{~g} / \mathrm{cm}^{3} .33$ A very small part of the intruded solution $(\sim 0.01 \mathrm{~mL} / \mathrm{g})$ is not expelled at the end of the first cycle, whereas in the following cycles the intrusion is fully reversible $\left(V_{\text {lnt }}=0.07 \mathrm{~mL} / \mathrm{g}\right)$ with no hysteresis between the intrusion and extrusion isotherms. Thus, the $\mathrm{Si}-\mathrm{DDR}-10 \mathrm{M} \mathrm{LiCl}$ system mainly shows shock-absorber behavior in the first cycle, while perfect spring behavior is observed in the second and in the third cycles.

The Si-DDR-20 M LiCl system in the first cycle is characterized first by the highest intrusion pressure value ever observed $(357 \mathrm{MPa})$ for a zeosil-based system and second by a large intruded volume, $0.26 \mathrm{~mL} / \mathrm{g}$. This value could be affected by a certain imprecision, but the order of magnitude is correct because this result was reproducible twice on two different samples (see below). The huge rise of the intrusion pressure compared to the value of water intrusion (6.0 times) was expected because it was already observed for other cage-type zeosils with $8 \mathrm{MR}$ pore openings (7.4 for the LTA-type one and 5.6 for CHA-type zeosil), ${ }^{23,34}$ while for channel-type ones this increase is typically lower. ${ }^{35}$ Conversely, the intruded volume value is not consistent with the microporous one determined from $\mathrm{N}_{2}$ adsorption-desorption measurements ( 0.26 against $0.15 \mathrm{~cm}^{3} / \mathrm{g}$, respectively). This could be due to the extraordinary high pressure that forces the aqueous solution inside of the cages that are not accessible to $\mathrm{N}_{2}$ molecules. The obtained value is in agreement with the total available pore volume per gram of DDR-type zeosil $\left(0.24 \mathrm{~cm}^{3} / \mathrm{g}\right.$; see the Introduction). Even if better filling of the porosity was already observed in a previous work for highly concentrated $\mathrm{LiCl}$ aqueous solutions, ${ }^{23}$ this result is surprising because the totality of the porosity filling was never achieved. Besides, it was believed that small cages with pore openings at $6 \mathrm{MR}$ and lower were not accessible to water molecules during high-pressure intrusion-extrusion experiments. ${ }^{36}$

The extrusion of the liquid seems to occur in different steps even if they are not well pronounced. The corresponding extrusion pressures range from 275 to $75 \mathrm{MPa}$, probably because the liquid is intruded into small cages that hinder the outflow. The average value of extrusion pressure corresponding to half of the volume variation is $130 \mathrm{MPa}$. The extrusion is not totally reversible; a very small volume of the liquid $(\sim 0.02 \mathrm{~mL} /$ g) remains inside of the pores. Thus, the Si-DDR-20 M LiCl system demonstrates a combination of bumper and predominant shock-absorber behavior in the first cycle. In second and following cycles, the intrusion pressure is lower than that in the first one but remains very high $\left(P_{\text {int }}=253 \mathrm{MPa}\right)$, and the system shows a fully reversible shock-absorber behavior with a yield of $51 \%$. It should be noticed that such shock-absorber behavior with large hysteresis is not typical for zeosil-based systems, where spring (fully reversible with small hysteresis) or bumper behaviors (irreversible intrusion) are usually observed. Another unusual phenomenon of Si-DDR-based systems is the transition from a completely reversible behavior for water intrusion to a slight irreversible one for the intrusion of $\mathrm{LiCl}$

Table 2. Characteristics of the "Si-DDR-Water" and "Si-DDR-LiCl Aqueous Solutions" Systems ${ }^{a}$

\begin{tabular}{|c|c|c|c|c|c|c|c|}
\hline system & $P_{\text {int }}^{b}\left[\mathrm{MP}_{2}\right]$ & $p_{e x}^{b}\left[\mathrm{MP}_{2}\right]$ & $V_{\text {ing }}{ }^{b}[\mathrm{~mL} / \mathrm{g}]$ & $V_{\alpha}^{b}[\mathrm{~mL} / \mathrm{g}]$ & $E_{2}=[\mathrm{J} / \mathrm{g}]$ & $E_{q}^{d}[\mathrm{D} / \mathrm{g}]$ & yield $(\%)$ \\
\hline $\mathrm{Si}-\mathrm{DDR}-\mathrm{H}_{2} \mathrm{O}^{1822 \mathrm{~s}}$ & 60 & 51 & 0.11 & 0.11 & 6.7 & 5.7 & 85 \\
\hline Si-DDR-10 M LiCl & $193^{f}$ & 166 & $00 e^{f}$ & 0.07 & $15,4^{f}$ & 11.6 & $7 f^{f}$ \\
\hline & $166^{8}$ & 166 & $2 \sigma^{s}$ & 0.07 & $11.6^{8}$ & 11.6 & $100^{8}$ \\
\hline Si-DDR-20 M LiCh & $357^{f}$ & 130 & $0.26^{f}$ & 0.24 & $9 \mathcal{f}^{f}$ & 31 & $3 f^{f}$ \\
\hline & $253^{g}$ & 130 & $024^{5}$ & 0.24 & $61^{\varepsilon}$ & 31 & $51^{\varepsilon}$ \\
\hline
\end{tabular}

"Variables: Intrusion $\left(P_{\mathrm{in}}\right)$ and extrusion $\left(I_{\alpha x}\right)$ pressures, intruded $\left(V_{\mathrm{ret}}\right)$ and extruded $\left(V_{\mathrm{\alpha e}}\right)$ volumes, and stored $\left(E_{\mathrm{s}}\right)$ and restored $\left(E_{\mathrm{r}}\right)$ energies.

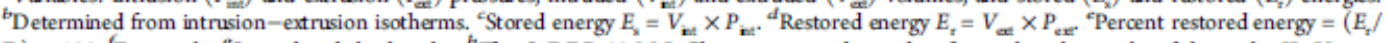
$\left.E_{2}\right) \times 100 .{ }^{f}$ First cycle. ${ }^{g}$ Second and third cycles. ${ }^{h}$ The Si-DDR-20 M LiCl system was subjected to five cydes; the results of the cycles II-V were superimposable. 
aqueous solutions because normally an opposite trend is observed. ${ }^{22,23,34}$

Due to the extraordinary intrusion pressure and intruded volume observed, the highest absorbed energy values ever obtained for a zeosil-based system were recorded for the $\mathrm{Si}$ DDR-20 M LiCl system: 93 and $61 \mathrm{~J} / \mathrm{g}$ for the first and the following cycles, respectively, three times higher than the values reported in literature. 23,37

X-ray Diffraction. The XRD patterns of pure-silica DDRtype zeolite samples are reported in Figure 2. The patterns

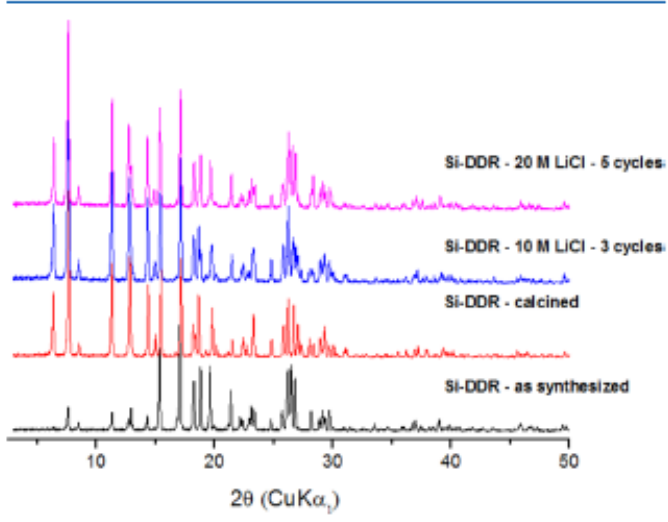

Figure 2. XRD patterns of the Si-DDR samples in the as-synthesized form and calcined forms before and after three and five intrusionextrusion cydes in 10 and $20 \mathrm{M} \mathrm{LiCl}$ aqueous solutions, respectively.

before and after the water intrusion-extrusion experiments are quite similar (not shown), which means that at long-range order the structure is not affected. Conversely, an interesting phenomenon is observed after 10 and $20 \mathrm{M} \mathrm{LiCl}$ aqueous solution intrusion-extrusion experiments (a magnification of Figure 2 is depicted in Figure 3). After three $(10 \mathrm{M} \mathrm{LiCl})$ and five cycles $(20 \mathrm{M} \mathrm{LiCl})$, the XRD patterns of the intrudedextruded samples are different from the one obtained for the nonintruded sample (Si-DDR calcined sample in Figure 3). There are a lot of similarities between these XRD patterns and the one of the as-synthesized sample (containing the organic template), in particular, for the Si-DDR-20 M LiCl sample. Most of the similarities are observed in the $14-31^{\circ} 2 \theta$ range (Figure 3). The positions (but not the shape) of some peaks are slightly different from the one found in the XRD pattern of the as-synthesized sample. This could be ascribed to the slight change in the cell parameters that are more similar to the ones of the as-synthesized product than to those of the calcined (nonintruded) one (see Table 3).

Table 3. Cell Parameters of Si-DDR Samples before and after Calcination and after the Intrusion-Extrusion Experiments with the $20 \mathrm{M} \mathrm{LiCl} \mathrm{Aqueous} \mathrm{Solution}$

\begin{tabular}{lccc}
\multicolumn{1}{c}{ sample } & \multicolumn{1}{c}{$(\mathrm{A})$} & \multicolumn{1}{c}{$c(\mathrm{~A})$} & \multicolumn{1}{c}{$\boldsymbol{V}\left(\mathrm{A}^{3}\right)$} \\
Si-DDR (as-synthesized) & $13.887(3)$ & $40.958(9)$ & $6840.4(18)$ \\
Si-DDR (calcined) & $13.754(3)$ & $41.393(10)$ & $6781.5(18)$ \\
Si-DDR-20 M LiCl & $13.855(4)$ & $40.950(14)$ & $6807.2(26)$
\end{tabular}

The XRD pattern of the sample intruded with the $10 \mathrm{M} \mathrm{LiC}$ aqueous solution seems to be a mixture of the ones of the calcined and as-synthesized samples. This feature is well visible in the range of $26.5-27.5^{\circ} 2 \theta$, where instead of two single peaks observed in the patterns of the calcined sample and $20 \mathrm{M}$ $\mathrm{LiCl}$ intruded sample two double peaks (4 peaks) are observed in the XRD pattern of the $10 \mathrm{M} \mathrm{LiCl}$ intruded sample. Therefore, XRD analysis seems to indicate that in the $20 \mathrm{M}$ $\mathrm{LiCl}$ intruded sample the "as-synthesized component" is predominant, while for the $10 \mathrm{M} \mathrm{LiCl}$ intruded one it is composed of a mixture of the XRD patterns of the assynthesized and the calcined one, but the latter is the more visible. It could be hypothesized that the nonexpelled water molecules or $\mathrm{Li}$ and $\mathrm{Cl}$ ions trapped inside of the porosity after the first intrusion cycle lead to modification of the XRD pattern, as was observed for the as-synthesized material with the organic structure-directing agent. This hypothesis could be supported by the XRD pattern of the Si-DDR sample intruded with $20 \mathrm{M} \mathrm{LiCl}$ aqueous solution after calcination at $350{ }^{\circ} \mathrm{C}$ (not shown), which is superimposable with the one of the calcined sample. Another explanation could be ascribed to the higher intrusion pressure observed for the sample intruded with the $20 \mathrm{M} \mathrm{LiCl}$ aqueous solution that leads to distortions of the

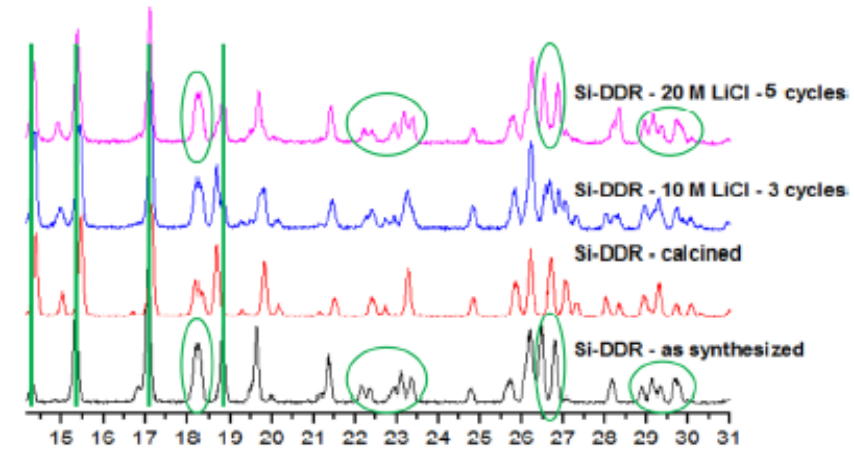

$2 \theta\left(\mathrm{CuK}_{1}\right)$

Figure 3. Magnification of Figure 2 in the $14-31^{\circ} 2 \theta$ range. Green circles and lines indicate the similarities between the patterns of the assynthesized and $20 \mathrm{M} \mathrm{LiO}$ intruded-extruded samples. 
a)

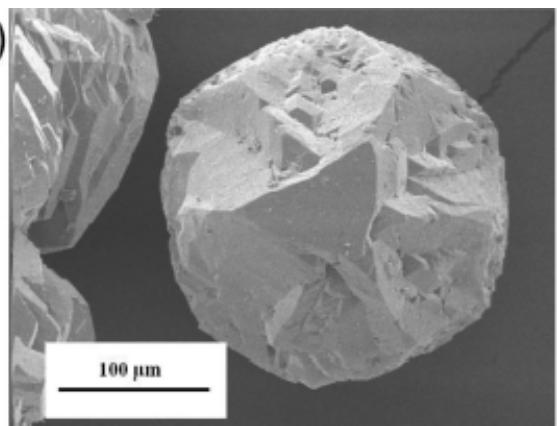

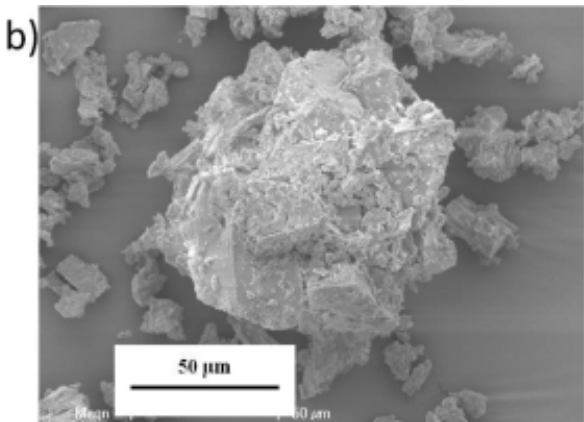

Figure 4. SEM micrographs of Si-DDR samples before (a) and after (b) three intrusion-extrusion cydes in the $10 \mathrm{M} \mathrm{LiCl}$ aqueous solution.

DDR unit cell. When the cell parameters of the as-synthesized and of the calcined products are converted from the hexagonal to the rhombohedral cell, only a slight difference $(0.5 \%)$ is observed between the $a$ rmomb unit cell parameters (15.83 and $15.92 \AA$, respectively). A more pronounced variation $(\sim 1.6 \%)$ is found for the $\alpha_{\text {rhamb }}$ angle ( 52.02 and $51.19^{\circ}$, respectively). Thus, the two unit cells are quite similar except for the distortion of the $\alpha_{\text {ano }}$ angle. Because the XRD pattern of the sample intruded with $20 \mathrm{M} \mathrm{LiCl}$ aqueous solution is more similar to that of the as-synthesized one (as shown in Figure 3 and in Table 3), it is probable that the high pressure and/or the slight amount of the nonextruded liquid induces a distortion of the unit cell leading to a $\alpha_{\text {rhomb }}$ angle more similar to the one of the as-synthesized material $\left(a_{\text {homb }}=15.82 \AA\right.$ and $\alpha_{\text {romb }}=$ $\left.51.94^{\circ}\right)$.

In order to better understand the cause of this change in the zeosil structure, another test was made on another sample of DDR-type zeosil (DDR 022 sample; see XRD patterns in Supporting Information Figure S1). This sample was analyzed after three and five intrusion-extrusion cycles with $20 \mathrm{M} \mathrm{LiCl}$ aqueous solution. Surprisingly, after three cycles, the long-range order is not affected; the XRD pattern is similar to that of the calcined sample. Only after five cycles is a change observed (XRD patterns similar to that of the as-synthesized sample) The fact that the change in the structure occurs after a different number of cycles (three and five cycles for 10 and $20 \mathrm{M} \mathrm{LiCl}$ concentrated solutions, respectively) could indicate that the nature of the liquid leads to a different interaction with the pore walls of the material. When the $10 \mathrm{M} \mathrm{LiCl}$ aqueous solution is intruded, a higher amount of free water molecules can interact with the cage walls, whereas for the $20 \mathrm{M} \mathrm{LiCl}$ aqueous solution, all water molecules are included in the solvation sphere of the ions; thus, more cycles are required to affect the zeosil framework

Scanning Electron Microscopy. The Si-DDR samples were examined by SEM before (Figure 4a) and after (Figure 4b) intrusion-extrusion experiments. The sample consists of big polyhedral crystals with a diameter of $\sim 100-200 \mu \mathrm{m}$. After intrusion-extrusion experiments (the sample intruded with the $10 \mathrm{M} \mathrm{LiCl}$ aqueous solution is shown in Figure $4 \mathrm{~b}$ as an example), the crystals are broken and damaged.

$\mathrm{N}_{2}$ Adsorption-Desorption Isotherms. The $\mathrm{N}_{2}$ adsorption-desorption isotherms of the nonintruded and LiC aqueous solution intruded samples are shown in Figure 5. Whatever the outgassing temperature $\left(90\right.$ or $300^{\circ} \mathrm{C}$ ), the BET surface area and the microporous volume of the nonintruded

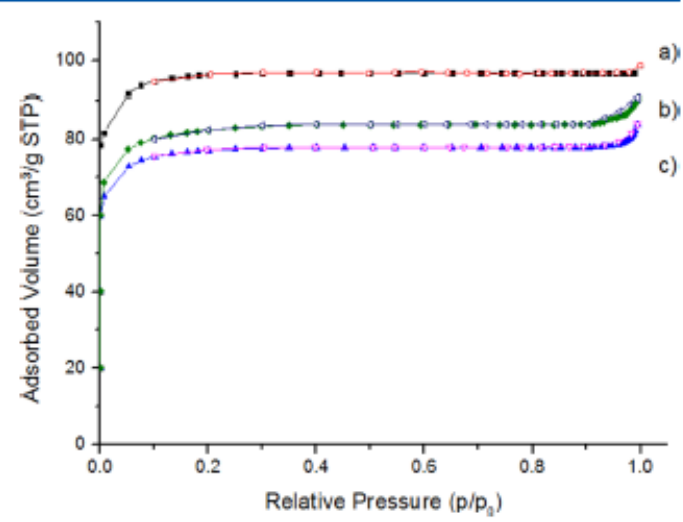

Figure 5. $\mathrm{N}_{2}$ adsorption-desorption isotherms at $77 \mathrm{~K}$ of the Si-DDR sample before (a) and after five and three intrusion-extrusion experiments in (b) 20 and (c) $10 \mathrm{M} \mathrm{LiCl}$ aqueous solutions, respectively. (Filled symbols: adsorption curves; empty symbols: desorption arves.)

sample are $\sim 380 \mathrm{~m}^{2} / \mathrm{g}$ and $\sim 0.15 \mathrm{~cm}^{3} / \mathrm{g}$ respectively. Slightly lower values are found for the intruded samples, $297 \mathrm{~m}^{2} / \mathrm{g}, 0.12$ $\mathrm{cm}^{3} / \mathrm{g}$ and $316 \mathrm{~m}^{2} / \mathrm{g}, 0.13 \mathrm{~cm}^{3} / \mathrm{g}$ for the samples intruded with 10 and $20 \mathrm{M} \mathrm{LiCl}$ aqueous solutions, respectively, which could indicate the creation of few defect sites.

Thermogravimetric Analysis. The experimental results issued from TG of the Si-DDR samples before and after the intrusion-extrusion experiments are depicted in Figure 6. The total weight loss ranges from $1.0 \mathrm{wt} \%$ for the nonintruded sample, revealing thus its high hydrophobic character, to $3.2 \mathrm{wt}$ $\%$ for the $20 \mathrm{M} \mathrm{LiCl}$ intruded one.

The weight losses occur in three main steps. The first one, situated between 30 and $150^{\circ} \mathrm{C}$, is ascribed to desorption of the physisorbed water molecules and corresponds to $0.7 \mathrm{wt} \%$ for the nonintruded sample and to 1.4 and $1.6 \mathrm{wt} \%$ for the 10 and $20 \mathrm{M} \mathrm{LiCl}$ intruded samples, respectively. The second one, in the temperature range of $150-350^{\circ} \mathrm{C}(\sim 0.2 \mathrm{wt} \%$ before the intrusion cycles and 0.6 and 0.7 wt \% after intrusion with 10 and $20 \mathrm{M} \mathrm{LiCl}$ aqueous solutions, respectively), could be assigned to strongly physisorbed water molecules, perhaps occluded in the zeosil cages because this weight loss is not very visible before the intrusion cycles. The third weight loss, comprised between 350 and $800{ }^{\circ} \mathrm{C}$ and that occurs for the 


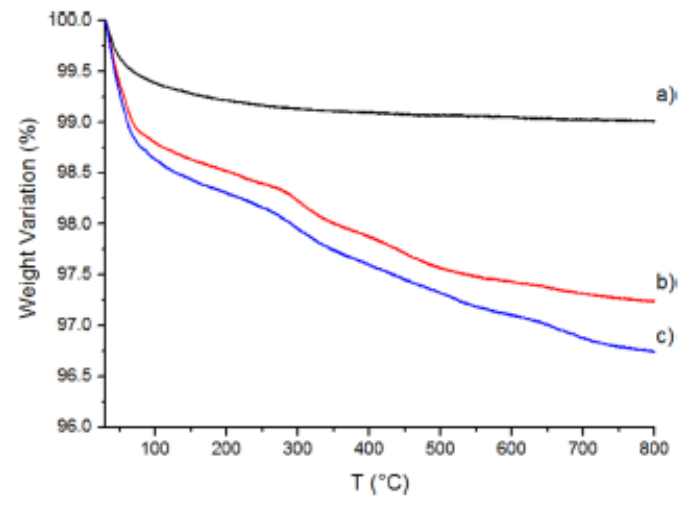

Figure 6. TG curves of the Si-DDR samples before (a) and after three and five intrusion-extrusion cydes in (b) 10 and (c) $20 \mathrm{M} \mathrm{LiC}$ aqueous solutions, respectively.

intruded samples in two badly pronounced steps, is probably due to water arising from dehydroxylation reactions. It corresponds to $\sim 1-\mathrm{OH}$ group per unit cell $\left(\mathrm{Si}_{120} \mathrm{O}_{240}\right)$ for the nonintruded sample $(0.1 \mathrm{wt} \%)$ and to 6 and $8-\mathrm{OH}$ groups for $10 \mathrm{M}(0.8$ wt $\%)$ and $20 \mathrm{M}(1.0$ wt $\%) \mathrm{LiCl}$ intruded samples, respectively. The difference found between 10 and 20 $\mathrm{M} \mathrm{LiCl}$ intruded samples is in correlation with the ones observed from XRD patterns.

${ }^{29} \mathrm{Si}$ MAS NMR Spectroscopy. The ${ }^{29} \mathrm{Si}$ MAS NMR spectra of the Si-DDR samples before and after intrusionextrusion experiments are shown in Figure 7. The spectrum of the nonintruded sample shows six resonances at -112.1 , $-112.8,-113.5,-119.2,-121.3$, and $-122.7 \mathrm{ppm}$ corresponding to $Q_{4}$ groups that can be ascribed to the seven nonequivalent crystallographic silicon sites of the DDR framework. ${ }^{38}$ The approximate relative intensities of these six resonances found by deconvolution of the spectrum are 1:3:9 $(3+6): 3: 3: 1$, which is in perfect agreement with the number of equivalent crystallographic sites for each nonequivalent crystallographic position: 6:18:54 $(18+36): 18: 18: 6$. The sharp peaks indicate a good crystalline order. After $\mathrm{LiCl}$ aqueous solution intrusion-extrusion experiments, some important differences are observed in the spectra of the corresponding DDR samples, confirming thus that modifications occurred in the zeosil framework. For the $20 \mathrm{M} \mathrm{LiCl}$ intruded sample, eight resonances are observed at -111.0 , $-113.0,-113.5,-119.0,-120.8,-121.3,-122.6$, and -123.1 ppm and the peaks become broader. This spectrum resembles the one of the as-synthesized sample ${ }^{38}$ even if it maintains some features of the calcined one (more visible than in the XRD pattern because the NMR technique is more sensitive). In fact, the NMR spectrum of the $20 \mathrm{M} \mathrm{LiCl}$ intruded sample corresponds to a mixture of the spectrum of the calcined sample (minor component) with a form similar to the spectrum of the as-synthesized one (major component; see arrows in Figure 7). Conversely, the spectrum obtained for the sample after the $10 \mathrm{M} \mathrm{LiCl}$ aqueous solution intrusion experiment seems to be intermediate between the ones of the $20 \mathrm{M} \mathrm{LiCl}$ intruded sample and the calcined (predominant) one. Therefore, these results confirm the ones found by XRD analysis.

In the spectra depicted in Figure 7 , no resonance corresponding to $\mathrm{Q}_{3}$ and $\mathrm{Q}_{2}\left(\mathrm{OH}-\mathrm{Si}-\left(\mathrm{OSi}_{3}\right)_{3}\right.$ or ${ }^{-} \mathrm{O}-\mathrm{Si}-$ $(\mathrm{OSi})_{3}$ and $(\mathrm{OH})_{2}-\mathrm{Si}-(\mathrm{OSi})_{2}$, respectively) sites is observed, indicating that the number of defect sites is too low to be detected by this technique. This result is quite surprising because TG curves indicate a quite significant content of $\equiv \mathrm{Si}-$ $\mathrm{OH}$ groups corresponding to $\sim 6 \%$ of the total ${ }^{29} \mathrm{Si}$ observed signal for the Si-DDR-20 M LiCl sample. It cannot be excluded that the weight loss observed at $T>600^{\circ} \mathrm{C}$ on the TG curves of the $\mathrm{LiCl}$ intruded samples might also be due to the removal of chloride compounds (formation of lithium silicates), as was clearly shown in a previous study, ${ }^{39}$ leading thus to a lower amount of silanol groups.

${ }^{1} \mathrm{H}{ }^{29} \mathrm{Si}$ CPMAS NMR Spectroscopy. The corresponding ${ }^{1} \mathrm{H}-{ }^{29} \mathrm{Si}$ CPMAS NMR spectra of the Si-DDR samples are shown in Figure 8. ${ }^{1} \mathrm{H}-{ }^{29} \mathrm{Si}$ CPMAS NMR does not provide

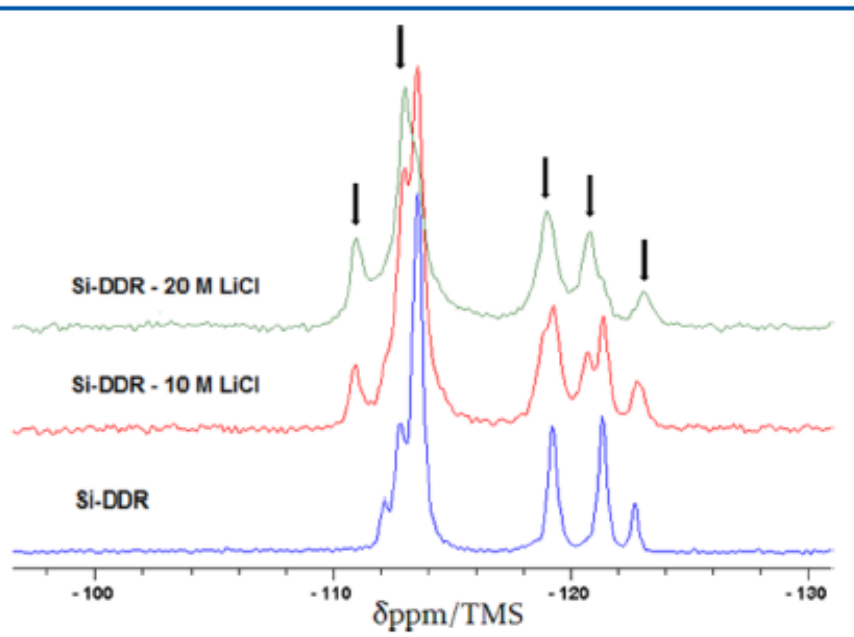

Figure 7. ${ }^{29} \mathrm{Si}$-MAS NMR spectra of the Si-DDR samples before and after three and five intrusion-extrusion cycles in 10 and $20 \mathrm{M} \mathrm{LiCl}$ aqueous solutions, respectively. Arrows correspond to components of the as-synthesized DDR-type zeosil (compare with ref 35). 


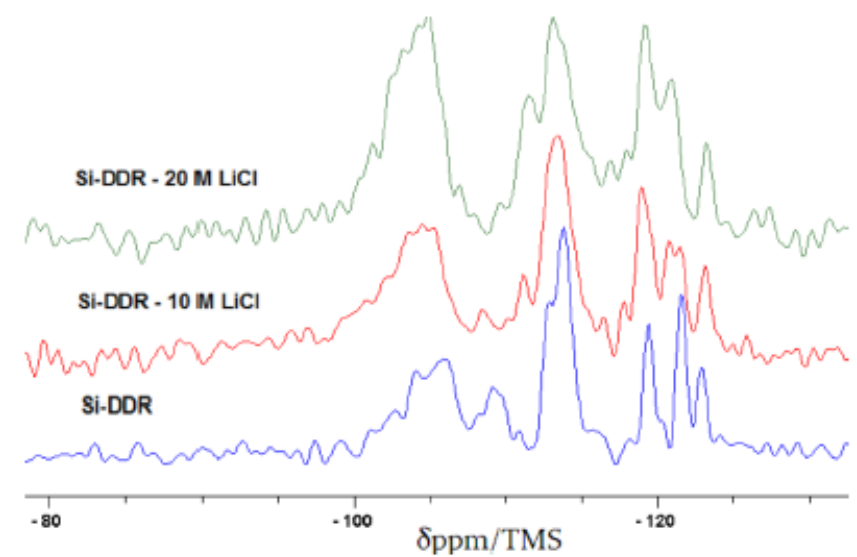

Figure 8. ${ }^{1} \mathrm{H}-{ }^{29} \mathrm{Si}-\mathrm{CPMAS}$ NMR spectra of the Si-DDR samples before and after three and five intrusion-extrusion cydes in 10 and $20 \mathrm{M} \mathrm{LiCl}$ aqueous solutions, respectively.

quantitative results; however, it allows a relative comparison of the spectra if they were registered under the same conditions. A broad resonance between -98.0 and $-108.0 \mathrm{ppm}$ corresponding to $\mathrm{Q}_{3}$ species is clearly detected in every spectrum. The relative intensity of this resonance increases considerably after the intrusion-extrusion experiments, which is in quite agreement with the $\mathrm{TG}$ results.

\section{- CONCLUSIONS}

The energetic performances of pure-silica DDR-type zeolite were studied by high-pressure intrusion-extrusion of water and $\mathrm{LiCl}$ aqueous solutions. A huge increase of the intrusion pressure with the $\mathrm{LiCl}$ concentration was observed: 60, 193, and $357 \mathrm{MPa}$ for water and 10 and $20 \mathrm{M} \mathrm{LiCl}$ aqueous solutions, respectively. The last value is the highest pressure value ever found for a zeosil-based system. A strong rise of the intruded volume was also observed for the $20 \mathrm{M} \mathrm{LiCl}$ solution. It increased from $0.08 \mathrm{~mL} / \mathrm{g}$ for the $10 \mathrm{M} \mathrm{LiCl}$ solution to 0.26 $\mathrm{mL} / \mathrm{g}$. This value is close to one of the total theoretical pore volume of the DDR-type zeosil, indicating a complete filling of the porosity. The combination of these two factors led to the highest density of absorbed mechanical energy ever observed for such systems (93 and $61 \mathrm{~J} / \mathrm{g}$ for the first and following cycles, respectively). While water intrusion is perfectly reversible (spring behavior) without no significant change for the DDR structure, the use of concentrated $\mathrm{LiCl}$ aqueous solutions has two consequences. The first one is the slightly irreversible intrusion in the first cycle (combination of bumper and shock-absorber behavior) and a perfect shock-absorber behavior for the following cycles with a large hysteresis (energy yield of $51 \%$ ). The second one is the slight change on the XRD patterns and ${ }^{29} \mathrm{Si}$ MAS NMR spectra. After five intrusionextrusion cycles, the $20 \mathrm{M} \mathrm{LiCl}$ intruded sample shows characteristics more similar to those of the as-synthesized sample than the calcined one, while after only three cycles, no modifications are observed in the XRD pattern. However, after three cycles, the sample intruded with $10 \mathrm{M} \mathrm{LiCl}$ aqueous solution presents characteristics similar to both the assynthesized and calcined (nonintruded) samples. Possible explanations could be the remaining molecules (ions) of the intruded liquid that play a role similar to that of the organic template in the as-synthesized material or the high pressure that induces a slight distortion of the zeosil structure.

\section{ASSOCIATED CONTENT}

(5) Supporting Information

The Supporting Information is available free of charge on the ACS Publications website at DOI: 10.1021/acs.jpcc.7b10995.

XRD patterns of the DDR 022 samples in the assynthesized form and in the calcined form before and after three and five intrusion-extrusion cycles in $20 \mathrm{M}$ $\mathrm{LiCl}$ aqueous solution (PDF)

\section{AUTHOR INFORMATION}

\section{Corresponding Authors}

*E-mail: andrey.ryzhikov@uha.fr (A.R.).

*E-mail: joel.patarin@uha.fr (J.P.).

ORCID $\odot$

T. Jean Daou: 0000-0002-9973-3372

Joël Patarin: 0000-0002-651 1-5357

Notes

The authors declare no competing financial interest.

\section{ACKNOWLEDGMENTS}

L.R. thanks the University of Haute Alsace (UHA) for their financial support for her Ph.D. grant. The authors would like to thank Ludovic Josien, Séverinne Rigolet, and Laure Michelin for their assistance in scanning electron microscopy, NMR analyses, and XRD measurements

\section{REFERENCES}

(1) Gies, H. Studies on Clathrasils. DX Crystal Structure of DecaDodecasil 3R, the Missing Link between Zeolites and Clathrasils. Z Kristallogr. - Cryst. Mater. 1986, 175, 93-104.

(2) van Koningsveld, H. Compendium of Zeolite Framework Types: Building Schemes and Type Characteristics; Elsevier Science \& Technology, 2007

(3) ZEOMICS: Zeolites and Microporous Structures Characterization helios.princeton.edu/zeomics/ (2014).

(4) Gascon, J.; Blom, W.; van Miltenburg, A.; Ferreira, A.; Berger, R. Kapteijn, F. Accelerated Synthesis of All-Silica DD3R and Its 
Performance in the Separation of Propylene/Propane Mixtures. Microporous Mesoporous Mater. 2008, 115, 585-593.

(5) Yang, S.; Cao, Z.; Arvanitis, A.; Sun, X.; Xu, Z.; Dong, J. DDRType Zeolite Membrane Synthesis, Modification and Gas Permeation Studies. J. Membr. Sci 2016, 505, 194-204.

(6) Bergh, J.; Zhu, W.; Kapteijn, F.; Moulijn, J. A.; Yajima, K.; Nakayama, K.; Tomita, T. Yoshida, S. Separation of $\mathrm{CO}_{2}$ and $\mathrm{CH}_{4}$ by a DDR Membrane. Res. Chem. Intermed. 2008, 34, 467-474.

(7) van den Bergh, J; Güoüyener, C;; Gascon, J; Kapteijn, F. Isobutane Dehydrogenation in a DD3R Zeolite Membrane Reactor. Chem. Eng. I. 2011, 166, 368-377.

(8) Kuhn, J.; Yaijima, K. Tomita, T.; Gross, J.; Kapteijn, F. Dehydration Performance of a Hydrophobic DD3R Zeolite Membrane. J. Membr. Sci. 2008, 321, 344-349.

(9) Egorov, V. S.; Portyanoy, A. G.j Sorokin, A. P.; Maltsev, V. G.; Voznesensky, R. M.; Ivchenko, A. P. Thermally sensitive starting device. Russian Patent 2138086, 1996

(10) Iwatsubo, T.; Sucu, C. V.; Ikenagao, M.; Yaguchio, K. Dynamic Characteristics of a New Damping Element Based on Surface Extension Principle in Nanopore. J. Sound Vib. 2007, 308, 579-590.

(11) Eroshenko, V. A. A New Paradigm of Mechanical Energy Dissipation. Part 1: Theoretical Aspects and Practical Solutions. Proc. Inst. Mech. Eng, Part D 2007, 221, 285-300.

(12) Eroshenko, V. A.; Piatiletov, L.; Coiffard, L.; Stoudenets, V. A New Paradigm of Mechanical Energy Dissipation. Part 2: Experimental Investigation and Effectiveness of a Novel Car Damper. Proc. Inst. Mech Eng, Part D 2007, 221, 301-312.

(13) Eroshenko, V. Eroshenko's Hydrocapillary Accumulator. Patent SU 1333870,1985 .

(14) Eroshenko, V. Heterogeneous Energy Accumulation or Dissipation Structure, Methods for Using Such Structure and Associated Apparatus. Patent WO1996018040 A1, 1996.

(15) Eroshenko, V. Heterogeneous Thermodynamical System, Eroshenko Cycle of Transformation of Thermal Energy into Mechanical Energy and Devices to Achieve It. CR Acad Sci Ukr. Ser. A $1990,10,79$

(16) Eroshenko, V. A. Hydrocapillary Accumulator. Patent SU $943444,1980$.

(17) Eroshenko, V. A. Fadeev, A. Y. Intrusion and Extrusion of Water in Hydrophobized Porous Silica Colloid J. 1995, 57, 446-449. (18) Eroshenko, V.; Regis, R. C.; Soulard, M.; Patarin, J. Energetics: A New Field of Applications for Hydrophobic Zeolites. J. Am. Chem. Soc. 2001, 123, 8129-8130.

(19) Tzanis, L.; Trzpit, M.; Soulard, M.; Patarin, J. Energetic Performances of Channel and Cage-Type Zeosils. J. Phys Chem. C 2012, 116, 20389-20395.

(20) Soulard, M.; Patarin, J. Process for High-Pressure Energy Storage by Solvation/Desolvation and Associated Storage Device. Patent FR2976030, 2012

(21) Han, A.; Lu, W; Kim, T; Chen, X.; Qiao, Y. Influence of Anions on Liquid Infiltration and Defiltration in a Zeolite Y. Phys Rev. E 2008, 78,031408 .

(22) Ryzhikov, A.; Khay, L; Nouali, H.; Daou, T. J.; Patarin, J. Drastic Change of the Intrusion-Extrusion Behavior of Electrolyte Solutions in Pure Silica *BEA-Type Zeolite. Phys. Chem. Chem. Phys. 2014, 16, $17893-17899$.

(23) Ryzhikov, A.; Ronchi, L.; Nouali, H.; Daou, T. J.; Paillaud, J.-L.; Patarin, J. High-Pressure Intrusion-Extrusion of Water and Electrolyte Solutions in Pure-Silica LTA Zeolite. J. Phys. Chem. C 2015, 119, 28319-28325.

(24) Trzpit, M.; Soulard, M.j Patarin, J. The Pure Silica Chabazite: A High Volume Molecular Spring at Low Pressure for Energy Storage. Chem. Lett. 2007, 36, 980-981.

(25) Trzpit, M. Synthèse et caractérisation de zéosils pour des applications en énergétique. Ph.D. Thesis, Université de Haute Alsace, 2008

(26) Washburn, E. W. Note on a Method of Determining the Distribution of Pore Sizes in a Porous Material. Proc. Natl Acad Sci. U. S. A. $1921,7,115-116$.
(27) Wang, P.; Anderko, A.; Young, R. D. Modeling Surface Tension of Concentrated and Mixed-Solvent Electrolyte Systems. Ind Eng. Chem. Res 2011, 50, 4086-4098

(28) Michelin-Jamois, M.; Picard, C.; Charlaix, E.; Vigier, G. Osmotic Pressure Effects upon Intrusion of Liquid Electrolytes inside Hydrophobic MOF's. ArXiv:14045318v1 Physicschem-Ph 2014, 1-4.

(29) Michelin-Jamois, M.; Picard, C.; Vigier, G.; Charlaix, E. Giant Osmotic Pressure in the Forced Wetting of Hydrophobic Nanopores. Phys. Rev. Lett. 2015, 115, 036101/1-036101/4.

(30) Han, A.; Lu, W.; Kim, T.; Punyamurtula, V. K.; Qiao, Y. The Dependence of Infiltration Pressure and Volume in Zeolite $\mathrm{Y}$ on Potassium Chloride Concentration. Smart Mater. Struct. 2009, 18, 024005 .

(31) Han, A.; Punyamurtula, V. K.; Qiao, Y. Effects of Cation Size on Infiltration and Defiltration Pressures of a MCM-41. Appl. Phys. Lett. 2008, 92, 153117 .

(32) Arletti, R.; Ronchi, L.; Quartieri, S.; Vezzalini, G.; Ryzhikov, A. Nouali, H.; Daou, T. J.; Patarin, J. Intrusion-Extrusion Experiments of $\mathrm{MgCl}_{2}$ Aqueous Solution in Pure Silica Ferrierite: Evidence of the Nature of Intruded Liquid by in Situ High Pressure Synchrotron XRay Powder Diffraction. Microporous Mesoporous Mater. 2016, 235, 253-260.

(33) Desbiens, N.; Demachy, L; Fuchs, A. H.; Kirsch-Rodeschini, H, Soulard, M.; Patarin, J. Water Condensation in Hydrophobic Nanopores. Angew. Chem, Int. Ed. 2005, 44, 5310-5313.

(34) Ronchi, L.; Ryzhikov, A.; Nouali, H.; Daou, T. J.; Patarin, J. Influence of $\mathrm{LiCl}$ Aqueous Solution Concentration on the Energetic Performances of Pure Silica Chabaite. New J. Chem. 2017, 41, 25862592.

(35) Ronchi, L.; Ryzhikov, A.; Nouali, H.; Daou, T. J.; Albrecht, S. Patarin, J. Extra Large Pore Opening CFI and DON-Type Zeosils for Medhanical Energy Storage Microporous Mesoporous Mater. 2018, 255, 211-219.

(36) Saada, M. A.; Soulard, M.; Marler, B.; Gies, H.; Patarin, J. HighPressure Water Intrusion Investigation of Pure Silica RUB-41 and SSOD Zeolite Materials. J. Phys Chem. C 2011, 115, 425-430.

(37) Khay, L; Daou, T. J.; Nouali, H.; Ryzhikov, A.; Rigolet, S. Patarin, J. High Pressure Intrusion-Extrusion of $\mathrm{LiCl}$ Aqueous Solutions in Silicalite-1 Zeolite: Influence on Energetic Performances. J. Phys. Chem. C 2014, 118, 3935-3941.

(38) Gucưyener, C.; van den Bergh, J.; Joaristi, A. M.; Magusin, P. C M. M.; Hensen, E. J. M.; Gascon, J.; Kapteijn, F. Facile Synthesis of the DD3R Zeolite: Performance in the Adsorptive Separation of Buta-1,3Diene and but-2-Ene Isomers. J. Mater. Chem. 2011, 21, 1838618397.

(39) Ryzhikov, A.; Nouali, H.; Daou, T. J.; Patarin, J.; Ouwehand, J.; Cleridk, S.; De Candk, E; Van Der Voort, P.; Martens, J. A. Periodic mesoporous organosilicas as porous matrix for heterogeneous lyophobic systems. Mioroporous Mesoporous Mater. 2018, 260, 166171 